\title{
Poly(dimethylsiloxane) and Poly[vinyltrimethoxysilane-co-2-(dimethylamino) ethyl methacrylate] Based Cross-Linked Organic-Inorganic Hybrid Adsorbent for Copper(II) Removal from Aqueous Solutions
}

\author{
Fábio A. B. Silva, ${ }^{a}$ Fátima A. Chagas-Silva, ${ }^{a}$ Fábio H. Florenzano ${ }^{b}$ and \\ Fábio L. Pissetti $*$,a \\ ${ }^{a}$ Instituto de Química, Universidade Federal de Alfenas (UNIFAL-MG), \\ 37130-000 Alfenas-MG, Brazil \\ ${ }^{b}$ Departamento de Engenharia de Materiais, Escola de Engenharia de Lorena, Universidade de São \\ Paulo (USP), 12602-810 Lorena-SP, Brazil
}

\begin{abstract}
An organic-inorganic hybrid adsorbent was prepared and its application for the uptake of $\mathrm{Cu}^{\mathrm{II}}$ ions from aqueous solutions was studied. The polymer network was composed of poly(dimethylsiloxane) (PDMS), vinyltrimethoxysilane (VTMS), and 2-(dimethylamino)ethyl methacrylate (DMAEMA), described as PDMS-net-P(VTMS-co-DMAEMA). The chemical groups, thermal stability and morphology of this hybrid adsorbent were characterized using techniques of attenuated total reflectance Fourier transform infrared spectroscopy (ATR-FTIR), differential scanning calorimetry (DSC), thermogravimetric analysis (TGA), and scanning electron microscopy (SEM). In adsorption studies, saturation of the active sites of the material was observed at $\mathrm{pH} 5$, after 3 days, with each gram of material capable of adsorbing $0.48 \mathrm{mmol}$ of copper(II). The fractionary-order and Sips models provided the best fits to the experimental data in kinetic and equilibrium studies of the adsorption process, respectively. Moreover, an acceptable reusability was found for this cross-linked organic-inorganic hybrid adsorbent after usage-regeneration cycles without significantly losing its original activity.
\end{abstract}

Keywords: poly(dimethylsiloxane), 2-(dimethylamino)ethyl methacrylate, polymer network, heavy metal ions removal, adsorption-desorption cycles

\section{Introduction}

The contamination of water resources with metal ions such as zinc, copper, nickel, mercury, cadmium, lead, and chromium has attracted much attention because of their non-biodegradable nature and tendency to accumulate in living organisms. ${ }^{1-3}$ Among these metals, copper is a trace element that is essential for the growth of plants, animals, and humans. However, excess of copper in the environment can threaten aquatic species and human health. For example, a high concentration of copper in the human body can damage the liver and kidneys. ${ }^{4,5}$ Therefore, it has become necessary to exploit practical techniques employed for efficiently removing copper from aqueous solutions.

Different methods have been used for the removal of heavy metal ions, including chemical precipitation, ion exchange, adsorption, membrane filtration, and

\footnotetext{
*e-mail: fabio.pissetti@unifal-mg.edu.br, flpissetti@gmail.com
}

electrochemical treatment technologies. ${ }^{6}$ Among these, adsorption is known to be one of the most effective and economical heavy metal separation methods for wastewater treatment. Furthermore, because of the reversible nature of most adsorption processes, the adsorbents can be regenerated using desorption processes. ${ }^{7}$

Organic-inorganic hybrid materials have attracted attention in the search for selective adsorbents that are stable and can be applied for the removal of metals from aqueous solutions..$^{712}$ Some of the most important characteristics that can be obtained with this type of material are thermal and mechanical stabilities derived from inorganic bonds, combined to hydrophilicity and selectivity from the organic functional groups. ${ }^{13}$

According to the literature, poly(dimethylsiloxane) (PDMS) $\left[-\mathrm{Si}\left(\mathrm{CH}_{3}\right)_{2}-\mathrm{O}-\right]_{\mathrm{n}}$, which belongs to the class of silicones or polysiloxanes, can be used as a matrix to obtain new chemically modified materials for metal adsorption. ${ }^{14-18}$ This polymer presents interesting features such as high 
flexibility, high thermal stability, high oxidation stability, low chemical reactivity, and low toxicity. ${ }^{19,20}$ Polysiloxanes networks can be prepared by condensation of the terminal silanol $(\mathrm{Si}-\mathrm{OH})$ with a crosslinker containing alkoxy or silanol functions. ${ }^{21,22}$ These reactions can be catalyzed by alkyl tin salts..$^{23}$ An example of a trifunctional crosslinker for this purpose is vinyltrimethoxysilane (VTMS) $\left[\mathrm{H}_{2} \mathrm{C}=\mathrm{CHSi}\left(\mathrm{OCH}_{3}\right)_{3}\right]$, which also features a vinyl group $\left(-\mathrm{CH}=\mathrm{CH}_{2}\right)$ in its structure that can be used to perform free radical polymerization..$^{24,25}$

Various organic functional groups can be incorporated into a material to be used in copper removal, such as the carboxyl, ${ }^{26}$ hydroxyl, ${ }^{27}$ amine,,${ }^{28}$ thiol, ${ }^{29}$ sulfonic,${ }^{30}$ and phosphoric ${ }^{31}$ groups. For example, 2-(dimethylamino) ethyl methacrylate (DMAEMA) $\left[\mathrm{CH}_{2}=\mathrm{C}\left(\mathrm{CH}_{3}\right)\right.$ $\mathrm{COOCH}_{2} \mathrm{CH}_{2} \mathrm{~N}\left(\mathrm{CH}_{3}\right)_{2}$ ] is a hydrophilic monomer with ester and tertiary amine groups in its structure, along with a vinyl function allowing its polymerization. According to the literature, DMAEMA-containing materials exhibit high efficiency when applied to the removal of heavy metals from aqueous solutions. ${ }^{1,4,32-36}$

This paper reports the preparation and characterization of an organic-inorganic hybrid material for the removal of copper(II) from aqueous solutions, based on PDMS as an inorganic precursor, VTMS as a crosslinker, and DMAEMA as an organic component with adsorbent potential.

\section{Experimental}

\section{Materials}

The following materials were used: vinyltrimethoxysilane 98\%, 2-(dimethylamino)ethyl methacrylate $98 \%$, poly(dimethylsiloxane) containing silanol terminals groups (viscosity 90-150 cSt), benzoyl peroxide, dibutyltin diacetate (all from Sigma-Aldrich, St. Louis, MO, USA) and toluene (Synth, Diadema, SP, Brazil). De-Hibit-200 resin (Polysciences, Warrington, PA, USA) was previously used to remove the inhibitor present from DMAEMA monomer.

\section{Preparation of P(VTMS-co-DMAEMA) and PDMAEMA}

Poly[vinyltrimethoxysilane-co-2-(dimethylamino)ethyl methacrylate] P(VTMS-co-DMAEMA) was prepared by free radical polymerization (FRP) of VTMS:DMAEMA with a molar ratio of 1:2, using benzoyl peroxide as initiator and toluene as the solvent. The reaction mixture was stirred using a magnetic stir-bar for $5 \mathrm{~h}$ at about $80{ }^{\circ} \mathrm{C}$, under reflux in a nitrogen atmosphere $\left(\mathrm{N}_{2}\right)$. To terminate the polymerization, the flask was immersed in ice water. The reaction product was reserved for the next step.
Poly[2-(dimethylamino)ethyl methacrylate] (PDMAEMA) was prepared as a reference material under the same conditions described above for the copolymer.

Preparation of polymer network based on PDMS and P(VTMS-Co-DMAEMA)

Poly(dimethylsiloxane) containing silanol terminals groups was added to the reaction product from the previous step at a weight ratio of 1:1 relative to VTMS. Dibutyltin diacetate was used as a catalyst ( $1 \%$ by weight relative to PDMS). This mixture was stirred for $30 \mathrm{~min}$. The resulting viscous solution was placed in Teflon ${ }^{\mathrm{TM}}$ petri dishes. After complete curing, the solid film obtained was immersed in water for 30 days to remove any unbound reagents from the network. After this period, the material was powdered and washed with tetrahydrofuran and ethanol to remove remaining residues and possible by-products of the PDMS chain condensation. Finally, the material was dried at $60{ }^{\circ} \mathrm{C}$ under vacuum for $48 \mathrm{~h}$. The polymer network was designated as PVD, i.e., PDMS-net-P(VTMSco-DMAEMA).

\section{Characterization methods}

Attenuated total reflectance Fourier transform infrared (ATR-FTIR) spectra were obtained using a Thermo Scientific spectrophotometer model Nicolet iS50 FT-IR (Waltham, MA, USA) with the Pike GladiATR accessory. The measurements were obtained at a $4 \mathrm{~cm}^{-1}$ resolution from 32 scans.

Curves of differential scanning calorimetry (DSC) were obtained using a Seiko Exstar 7020 (Torrance, CA, USA)

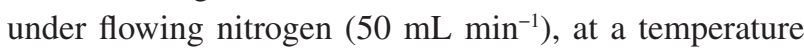
ranging from 15 to $75^{\circ} \mathrm{C}$ and a heating rate of $3{ }^{\circ} \mathrm{C} \mathrm{min}^{-1}$.

The thermogravimetric curves were acquired using TA Instruments equipment model TGA 2950 (New Castle, DE, USA). The measurements were performed under nitrogen $(100 \mathrm{~mL} \mathrm{~min}-1)$ at a heating rate of $20{ }^{\circ} \mathrm{C} \mathrm{min}^{-1}$ over a temperature range of $25-1100{ }^{\circ} \mathrm{C}$.

Micrographs were obtained using a Hitachi TM3000 (Tokyo, Japan) tabletop scanning electron microscope (SEM) with an accelerating voltage of $15 \mathrm{kV}$. The samples were first covered with a thin gold layer using a BalTec MED 020 sputtering instrument (Canonsburg, PA, USA).

\section{Swelling measurements in water}

Swelling measurements were performed using a PVD dry film $(20 \times 10 \times 2.5 \pm 0.5 \mathrm{~mm})$ with a known weight $(1.0336 \mathrm{~g})$. The sample was immersed in $200 \mathrm{~mL}$ of distilled 
water at $30{ }^{\circ} \mathrm{C}$. The weight of the swollen sample was measured periodically after rapid drying on filter paper. The amount of water adsorbed at time $\mathrm{t}$ per gram of film ( $\mathrm{g} \mathrm{H}_{2} \mathrm{O} \mathrm{g}^{-1}$ film), defined as $\mathrm{Q}_{\mathrm{w}}$, was calculated as follows: ${ }^{37}$

$\mathrm{Q}_{\mathrm{wt}}=\frac{\left(\mathrm{W}_{\mathrm{s}}-\mathrm{W}_{\mathrm{d}}\right)}{\mathrm{W}_{\mathrm{d}}}$

where $\mathrm{W}_{\mathrm{s}}$ is the weight of the swollen sample at time $\mathrm{t}(\mathrm{g})$, and $\mathrm{W}_{\mathrm{d}}$ is the weight of the dry sample $(\mathrm{g})$.

\section{Copper(II) adsorption study}

In this study, $100 \mathrm{mg}$ samples of the powdered material and $50 \mathrm{~mL}$ of a $\mathrm{CuCl}_{2}$ aqueous solution were placed in $125 \mathrm{~mL}$ Erlenmeyer flasks. The solutions were stirred for 3 days at $30^{\circ} \mathrm{C}$ using a Quimis Dubnoff bath model Q226M (Diadema, SP, Brazil).

The effect of the $\mathrm{pH}$ (1-5) was investigated using initial concentrations of $5 \mathrm{mmol} \mathrm{L}^{-1}$ of copper(II). The $\mathrm{pH}$ values were adjusted with dilute solutions of $\mathrm{HCl}$ and $\mathrm{NaOH}$ using a Bel Engineering pH meter model W3B (Monza, MB, Italy).

This study was performed up to $\mathrm{pH} 5$, because the precipitation of metal hydroxide occurs at higher $\mathrm{pH}$ values. ${ }^{38}$ The influence of the $\mathrm{pH}$ on the copper(II) adsorption was plotted as the adsorbed capacity $v s$. initial $\mathrm{pH}$, because it was possible to obtain the $\mathrm{pH}$ at which the adsorption reached the maximum capacity.

The study of the adsorption capacity was done using adsorption isotherms. Solutions were prepared with different molar concentrations of copper(II), ranging from 0.4 to $5 \mathrm{mmol} \mathrm{L}^{-1}$. The concentrations were determined using a flame atomic absorption spectrophotometer (FAAS; model AA-7000, Shimadzu, Tokyo, Japan).

The amount of adsorbed metal was determined by equation $2:{ }^{16}$

$\mathrm{q}_{\mathrm{e}}=\frac{\left(\mathrm{n}_{0}-\mathrm{n}_{\mathrm{e}}\right)}{\mathrm{m}}$

where $\mathrm{q}_{\mathrm{e}}$ is the amount of adsorbed metal at equilibrium per gram of material $\left(\mathrm{mmol} \mathrm{g}^{-1}\right) ; \mathrm{n}_{0}$ is the initial molar amount of metal (mmol) in solution; $n_{e}$ is the molar amount of metal in solution on the equilibrium (mmol); and $\mathrm{m}$ is the mass of the adsorbent ( $\mathrm{g}$ ).

\section{Kinetic and equilibrium models}

The kinetic and equilibrium models were fitted with a non-linear fitting method using OriginPro 8.5 software (OriginLab, Northampton, UK).
The following models were tested to evaluate the adsorption kinetics: pseudo-first order, ${ }^{39}$ pseudo-second order, ${ }^{40}$ chemisorption (Elovich), ${ }^{41}$ fractionary order (Avrami) ${ }^{42}$ and intraparticle diffusion. ${ }^{43}$

The isotherm models used to evaluate the equilibrium isotherm were: Langmuir, ${ }^{44}$ Freundlich,${ }^{45}$ Sips, ${ }^{46}$ and Redlich-Peterson. ${ }^{47}$

\section{Statistical evaluation of kinetic and isotherm parameters}

The models were evaluated using an error function $\left(\mathrm{F}_{\text {error }}\right)$, which measured the differences in the amounts of metal adsorbed by the adsorbent (q), as predicted by the models and measured experimentally, considering the number of parameters of the fitted model. Equation 3 shows how $\mathrm{F}_{\text {error }}$ was calculated: ${ }^{48}$

$$
F_{\text {error }}=\sqrt{\left(\frac{1}{n-p}\right) \sum_{i}^{n}\left(q_{i . e x p}-q_{i . \text { model }}\right)^{2}}
$$

where $\mathrm{n}$ is the number of experiments performed; $\mathrm{p}$ is the number of parameters of the fitted model; $q_{i, \text { exp }}$ is each value of q measured experimentally; and $\mathrm{q}_{\mathrm{i}, \text { model }}$ is each value of q predicted by the fitted model.

However, to define if the model is adequate to the experimental data, $F_{\text {exp }}$ value was calculated to compare the $\left(\mathrm{F}_{\text {error }}\right)^{2}$ (residual dispersion) with the dispersion of single experimental values $\left(\mathrm{S}_{\text {gexp }}\right)^{2}$ (standard deviation) as follows: ${ }^{48}$

$\mathrm{F}_{\text {exp }}=\frac{\left(\mathrm{F}_{\text {error }}\right)^{2}}{\left(\mathrm{~s}_{\mathrm{q}_{\text {exp }}}\right)^{2}}$

A comparison of it with the corresponding critical value $\left(\mathrm{F}_{\text {crit }}\right)$ was performed (5\% point of the $\mathrm{F}$ distribution for $(n-p)$ and $\alpha$ degrees of freedom. When $F_{\text {exp }}>F_{\text {crit }}$, the model cannot be considered as adequate to the adsorption system.

\section{Desorption and reuse studies}

The desorption experiments involved adding $100 \mathrm{mg}$ of copper ions-loaded hybrid adsorbent to $50 \mathrm{~mL}$ of $0.1 \mathrm{~mol} \mathrm{~L}^{-1}$ $\mathrm{HCl}$ solution. The mixture was shaken for $12 \mathrm{~h}$ to reach desorption equilibrium. Then, the material was separated from the solution by a filtration and washed with distilled water three times, and dried for reuse. Consecutive adsorptiondesorption cycles were repeated three times by using the same sample to determine the reusability of the material. The removal percentage after each run was determined by equation 5 , where $n_{0}$ and $n_{e}$ are the molar amount of copper(II) at the beginning and at equilibrium, respectively: 
$\%$ Removal $=100 \times \frac{\left(\mathrm{n}_{0}-\mathrm{n}_{\mathrm{e}}\right)}{\mathrm{n}_{0}}$

\section{Results and Discussion}

The first step describes the preparation of P(VTMS-coDMAEMA) by FRP of VTMS:DMAEMA, as reported in a previous work. ${ }^{49}$ Figure $\mathrm{S} 1$ (see Supplementary Information) show proton $\left({ }^{1} \mathrm{H}\right)$ nuclear magnetic resonance (NMR) spectrum of this copolymer at different ranges of chemical shift. Singlet at $2.370 \mathrm{ppm}$ was assigned to the $-\mathrm{N}\left(\mathrm{CH}_{3}\right)_{2}$, whereas, $-\mathrm{Si}-\mathrm{O}-\mathrm{CH}_{3}$ protons shows triplet at $3.240 \mathrm{ppm}$. Singlet at $1.429 \mathrm{ppm}$ aroused due to $-\mathrm{CH}_{2}$-(DMAEMA) attached to the other end of VTMS unit, while singlet at $1.175 \mathrm{ppm}$ was attributed to $-\mathrm{CH}_{2}-(\mathrm{VTMS})$ attached to the DMAEMA unit on one end. ${ }^{49}$ ATR-FTIR spectrum of P(VTMS-co-DMAEMA) (Figure S2) presented absorption bands between 1075-1212 $\mathrm{cm}^{-1}$ due to $\mathrm{Si}-\mathrm{O}-\mathrm{CH}_{2}$ vibrations. Absorption band at $1454 \mathrm{~cm}^{-1}$ was related to scissor vibrations of $-\mathrm{CH}_{2}$ and at $1722 \mathrm{~cm}^{-1}$ due to $\mathrm{C}=\mathrm{O}$ stretching vibrations. Absorption band at $2821 \mathrm{~cm}^{-1}$ was aroused due to $-\mathrm{CH}_{2}$ asymmetric vibrations. Bands between 1236 and $1058 \mathrm{~cm}^{-1}$ were observed due to stretching vibrations of tertiary amine groups. ${ }^{50,51}$ All these results suggest the formation of copolymer between VTMS and DMAEMA as represented in Scheme 1.
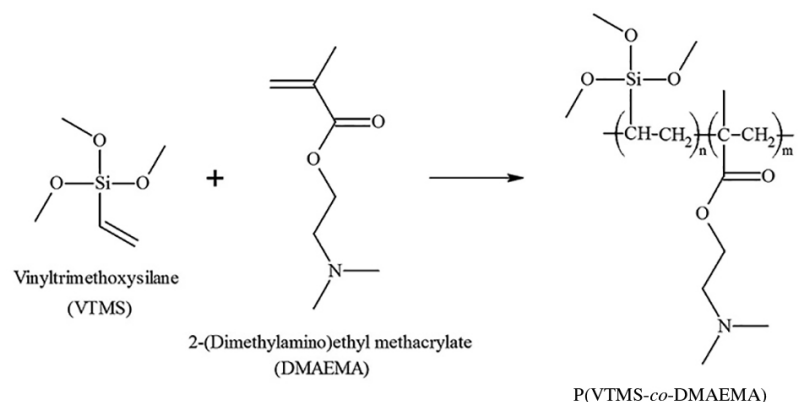

Scheme 1. Schematic representation of preparation of P(VTMS-coDMAEMA).

Scheme 2 illustrates the initial formation of the polymer network designated as PVD [PDMS-net-P(VTMS-coDMAEMA)]. In this step, polycondensation reactions are observed between silanol terminations ( $\mathrm{Si}-\mathrm{OH})$ of PDMS and methoxy functions of vinyltrimethoxysilane..$^{14-18,21,22}$

\section{Attenuated total reflectance Fourier transform infrared spectroscopy (ATR-FTIR)}

Figure 1 presents the infrared spectra for PDMS, VTMS, PDMAEMA, and PVD. For the PVD, bands were observed between 1100 and $1020 \mathrm{~cm}^{-1}$, those

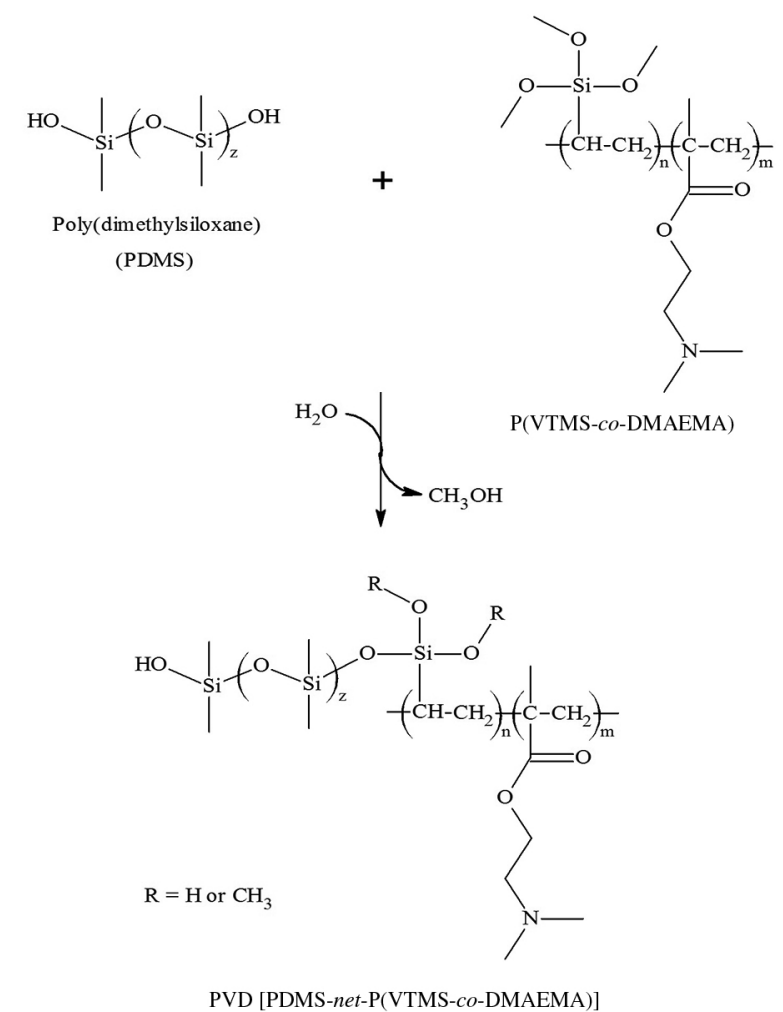

Scheme 2. Schematic representation of preparation of PVD [PDMS-net$\mathrm{P}(\mathrm{VTMS}-$ - $o$-DMAEMA)].

represent the asymmetric stretching of $\mathrm{Si}-\mathrm{O}-\mathrm{Si}$ and are characteristic of a PDMS polymeric network. ${ }^{14}$ The bands at 1408 and $1258 \mathrm{~cm}^{-1}$ were related to the asymmetric and symmetrical deformations of the $\mathrm{C}-\mathrm{H}$ bond of the $\mathrm{Si}\left(\mathrm{CH}_{3}\right)_{2}$ groups, respectively. The rocking deformation of $\mathrm{C}-\mathrm{H}$ and $\mathrm{Si}-\mathrm{C}$ bond stretching were observed at 843 and $790 \mathrm{~cm}^{-1}$, respectively. ${ }^{15}$ The band at $1728 \mathrm{~cm}^{-1}$ was related to $-\mathrm{C}(\mathrm{O}) \mathrm{O}-$ (ester) vibrational stretching derived from DMAEMA. ${ }^{50,51}$ These results suggest the inclusion of DMAEMA in the prepared PDMS network.

Thermal analyses: differential scanning calorimetry (DSC) and thermogravimetric analysis (TGA)

Figures $2 \mathrm{a}$ and $2 \mathrm{c}$ show DSC curves for PDMAEMA and PVD, respectively. The glass transition temperature $\left(\mathrm{T}_{\mathrm{g}}\right)$ characteristic of DMAEMA was observed at approximately $32{ }^{\circ} \mathrm{C}$ for both materials, ${ }^{52,53}$ indicating the formation of the polymer into the polymeric network.

The thermogravimetric analisis (TGA) and their derivatives (derivative thermogravimetric analysis, DTG) for PDMAEMA and PVD are presented in Figures $2 b$ and $2 d$, respectively. For PDMAEMA, a weight loss of about $50 \%$ was observed between 245 and $365{ }^{\circ} \mathrm{C}$, followed by another event between 365 and $475{ }^{\circ} \mathrm{C}$, until its complete decomposition..$^{54} \mathrm{PVD}$ was thermally stable up to $270{ }^{\circ} \mathrm{C}$. A 

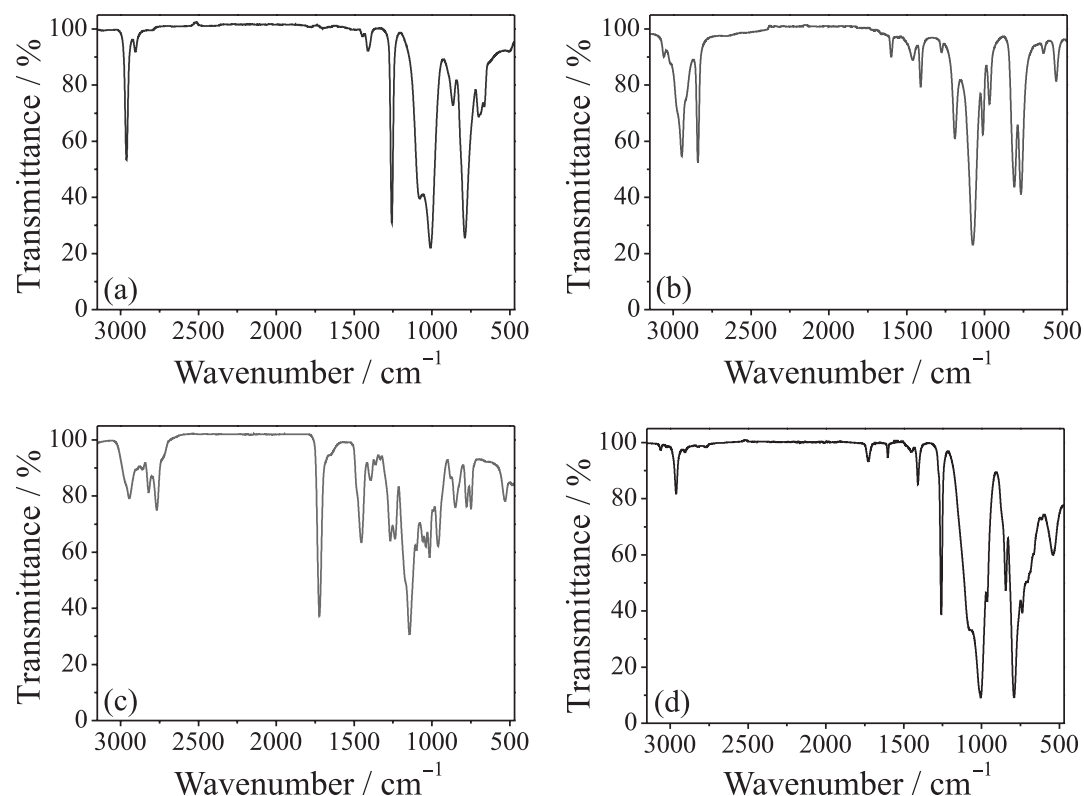

Figure 1. Fourier transform infrared spectroscopy (ATR-FTIR) spectra: (a) poly(dimethylsiloxane) (PDMS); (b) vinyltrimethoxysilane (VTMS); (c) poly[2(dimethylamino)ethyl methacrylate] (PDMAEMA); and (d) PDMS-net-P(VTMS-co-DMAEMA) (PVD).
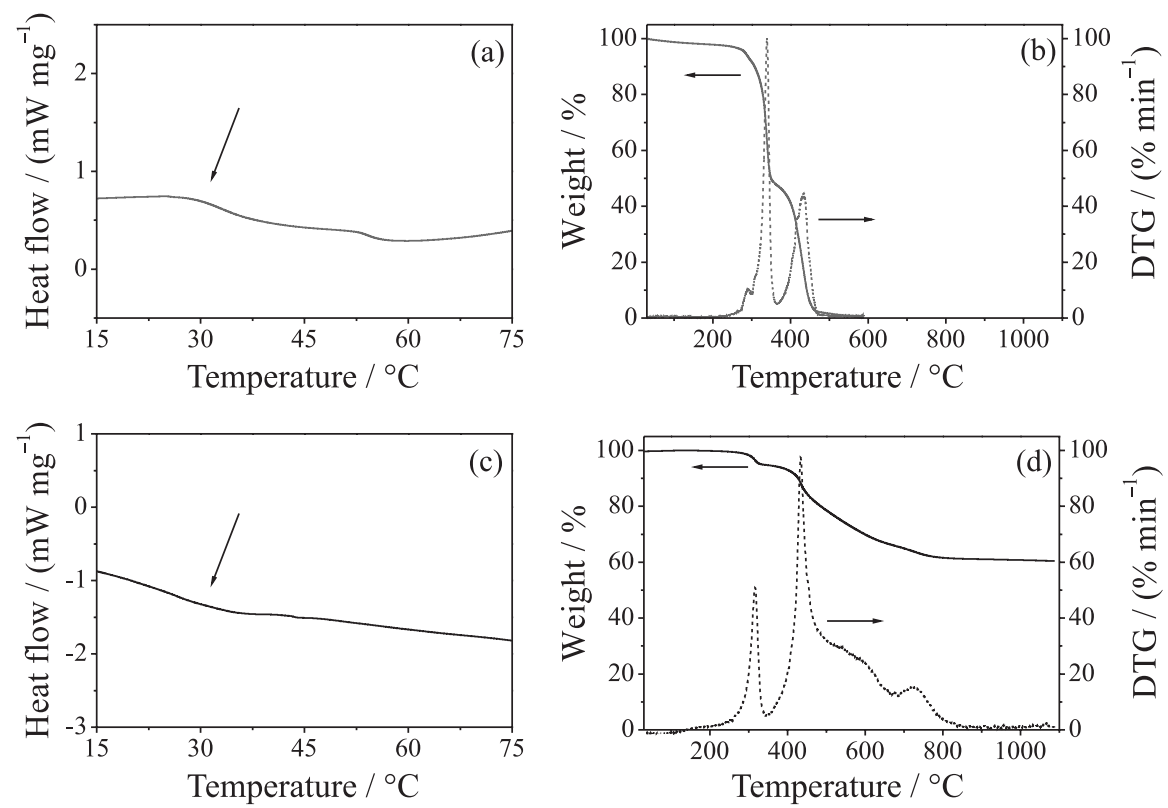

Figure 2. (a) Differential scanning calorimetry (DSC) for poly[2-(dimethylamino)ethyl methacrylate] (PDMAEMA); (b) thermogravimetric analysis (TGA) and differential thermal analysis (DTG) for PDMAEMA; (c) DSC for PVD; and (d) TGA and DTG for PDMS-net-P(VTMS-co-DMAEMA) PVD.

weight loss of $5 \%$ at $350{ }^{\circ} \mathrm{C}$ can be associated with the first DMAEMA degradation step. Next, another weight loss was observed associated with simultaneous events involving the final decomposition of DMAEMA and depolymerization of PDMS chains. A mass residue of $60 \%$ at $1100{ }^{\circ} \mathrm{C}$ is obtained, indicating a high degree of reticulation. ${ }^{22}$ Based on the value of the first weight loss, it is estimated that $10 \%$ of the material was composed of DMAEMA.

These results indicate the formation of a PDMS network with the incorporation of DMAEMA and a high rate of crosslinking, with the possible formation of silsesquioxane clusters with larger dimensions than those reported in the existing literature. ${ }^{15,18}$

\section{Scanning electron microscopy (SEM)}

Figure 3 shows SEM micrographs of PVD. According to the literature, pure PDMS materials exhibit a homogeneous, dense, and smooth surface, with a nonporous morphology. ${ }_{55,56}$ In Figures $3 a$ and $3 b$, it can be observed that the surface of 

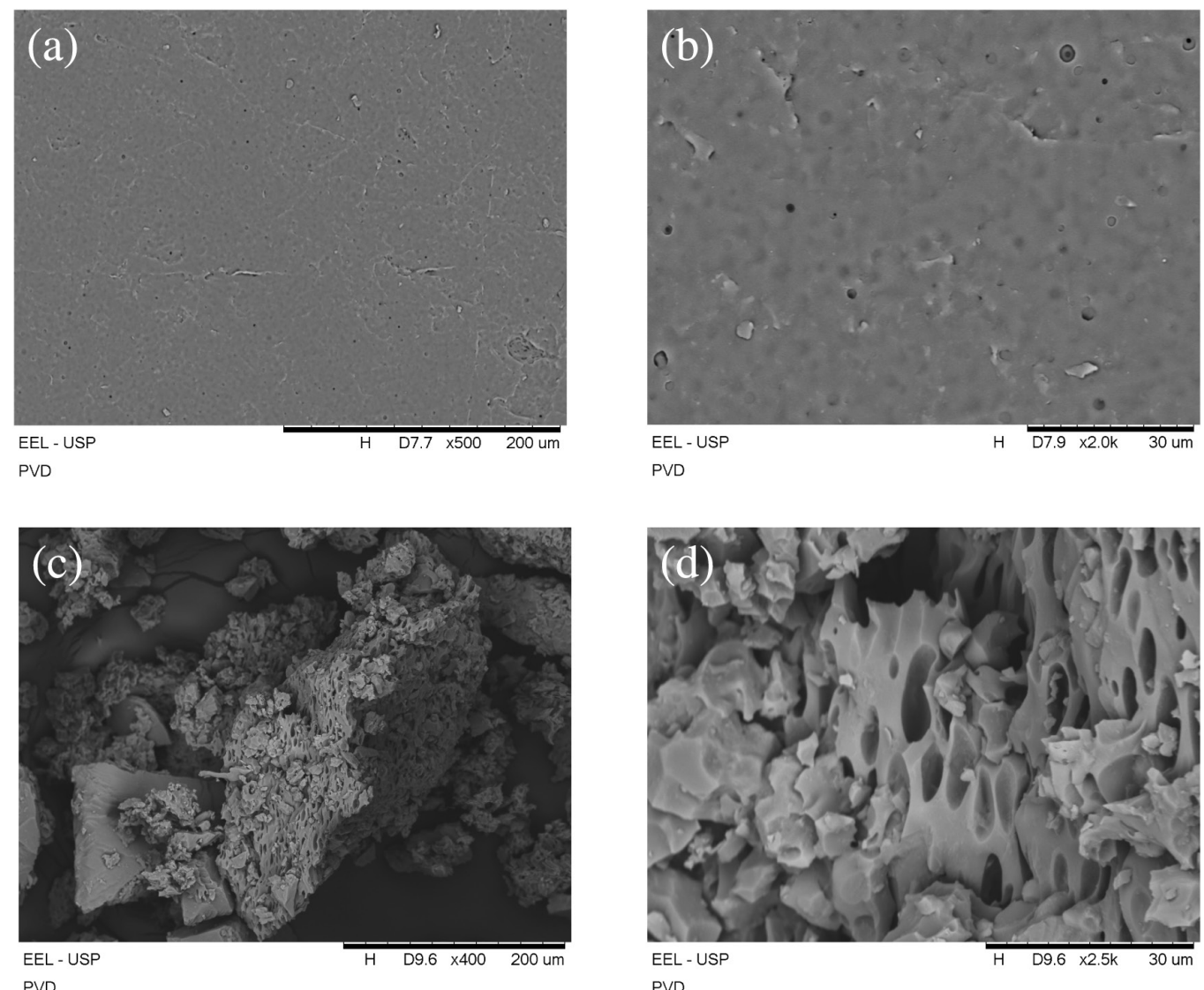

PVD

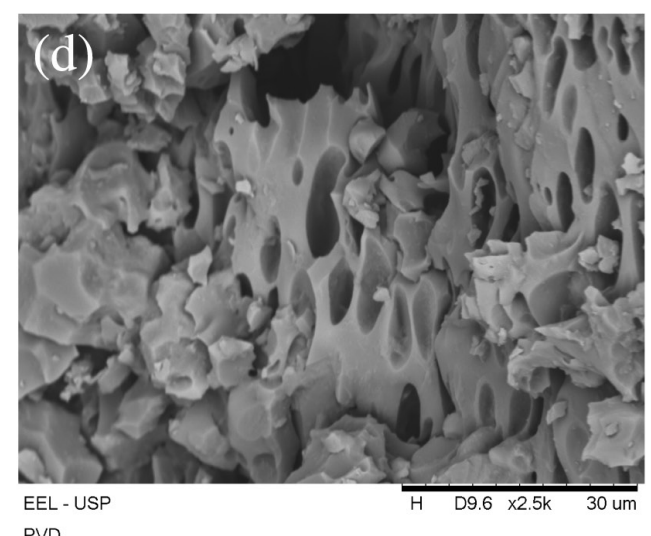

Figure 3. Scanning electron microscopy (SEM) micrographs of PDMS-net-P(VTMS-co-DMAEMA) (PVD) at different magnifications: (a), (b) film surface and (c), (d) powdered material.

the PVD film has a small number of pores. However, the micrographs from the fractures (Figures $3 \mathrm{c}$ and $3 \mathrm{~d}$ ) show a morphology with a higher degree of porosity. This pore formation of PVD indicates the presence of DMAEMA inside the modified PDMS network.

\section{Swelling measurements in water}

The swelling equilibrium (Figure 4) was reached at $0.24 \mathrm{~g} \mathrm{H}_{2} \mathrm{O} \mathrm{g}^{-1}$ film, after approximately 25 days. This time can be justified by the high hydrophobicity of PDMS, which hindered the diffusion of water into the film..$^{57,58}$ It is also interesting to note that, once equilibrium was reached, the water swelling remained practically constant until 40 days, indicating the absence of DMAEMA leaching phenomena during this period. This result indicates that PVD has the potential to be applied in an aqueous medium. However, the process is overall time-consuming and one of the main obstacles of the prepared adsorbent.

\section{Effects of $\mathrm{pH}$ on adsorption}

The $\mathrm{pH}$ of a solution can affect the surface charge and

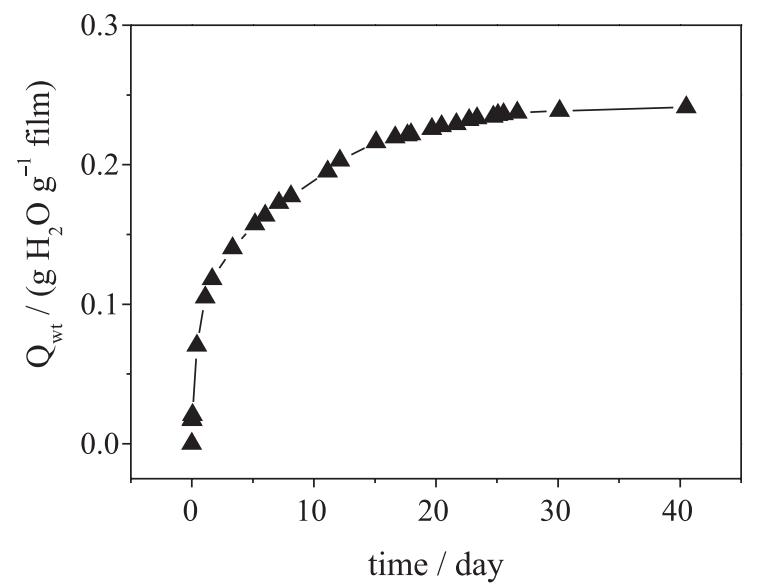

Figure 4. Amount of water adsorbed by PDMS-net-P(VTMS-coDMAEMA) (PVD) film $\left(\mathrm{Q}_{w}\right)$ vs. time.

degree of ionization of the adsorbents, which can lead to a shift in the process kinetics and equilibrium characteristics of the adsorption. ${ }^{59}$

The study of the initial $\mathrm{pH}$ effect on copper(II) adsorption capacity of PVD in water is presented in Figure 5. At acidic conditions, lower amount of copper ions was adsorbed due to the protonation of the amino group to form ammonium salts. With increase in the $\mathrm{pH}$ of the 


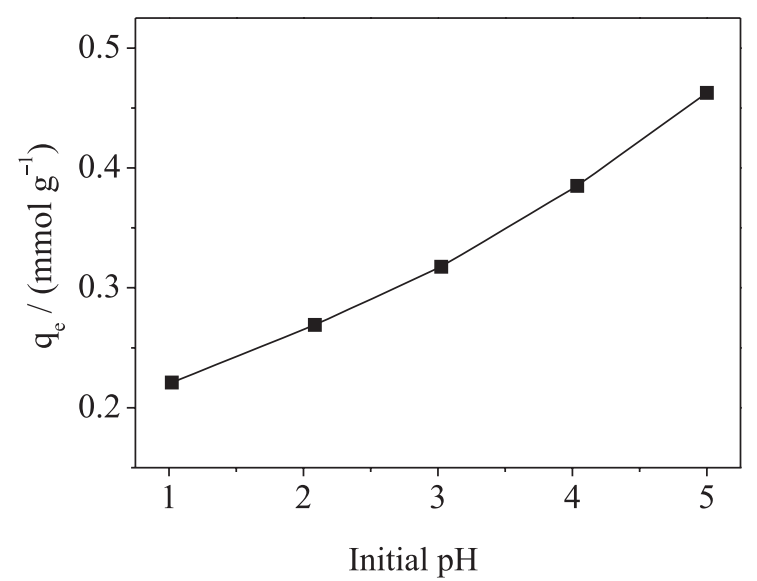

Figure 5. Effect of initial $\mathrm{pH}$ on copper(II) adsorption capacity of PDMSnet-P(VTMS-co-DMAEMA) (PVD) from aqueous solutions.

solution, the adsorbed amount of copper ion increased, reaching a maximum at $\mathrm{pH} 5$. This effect can be associated to a lower extension of protonation of amino groups due the higher $\mathrm{pH}$. Similar phenomenon was obtained for the sorption of $\mathrm{Cu}^{2+}$ ions on activated carbon functionalized with PDMAEMA. ${ }^{33}$

\section{Kinetic studies}

Figure 6 and Table 1 present the kinetic studies and parameter values of copper(II) adsorption for PVD from aqueous solutions, respectively. The adsorbent and adsorbate interaction time required to achieve equilibrium (or saturation) was measured to be 3 days ( $72 \mathrm{~h}$ ).

To study the adsorbate-adsorbent correlation over time, theoretical models were employed using a nonlinear adjustment method (Figure 6a). To all models studied $\mathrm{F}_{\text {exp }}<\mathrm{F}_{\text {crit }}$ showing that these can describe the experimental data of the kinetic studies.

The calculated $\mathrm{q}_{\mathrm{e}}$ values from the kinetic models of pseudo-first order, pseudo-second order and fractionary order were $0.499,0.667$ and 0.465 , respectively. When comparing with experimental $\mathrm{q}_{\mathrm{e}}(0.48)$, it can be observed that the pseudo-first order and fractionary order are closer. However, the fractionary model of Avrami was presented the best correlation, with the greatest determination factor $\left(\mathrm{R}^{2}=0.9983\right)$ and the minor error function $\left(\mathrm{F}_{\text {error }}=0.00614\right)$.

The intraparticle diffusion model was used to assess the effect of resistance on the mass transfer in the copper(II) adsorption by the active sites of the material. ${ }^{60}$ Figure $6 \mathrm{~b}$ shows the amount of adsorbed metal at time $t$ per gram of material $\left(\mathrm{q}_{\mathrm{t}}\right) v s$. the root square of time $\left(\mathrm{time}^{0.5}\right)$. According to this Weber-Morris model, the intraparticle diffusion may be considered as the rate-limiting step only in the case of linear dependence of $\mathrm{q}_{\mathrm{t}}$ on time $\mathrm{e}^{0.5 .{ }^{43}}$ The multilinearity of
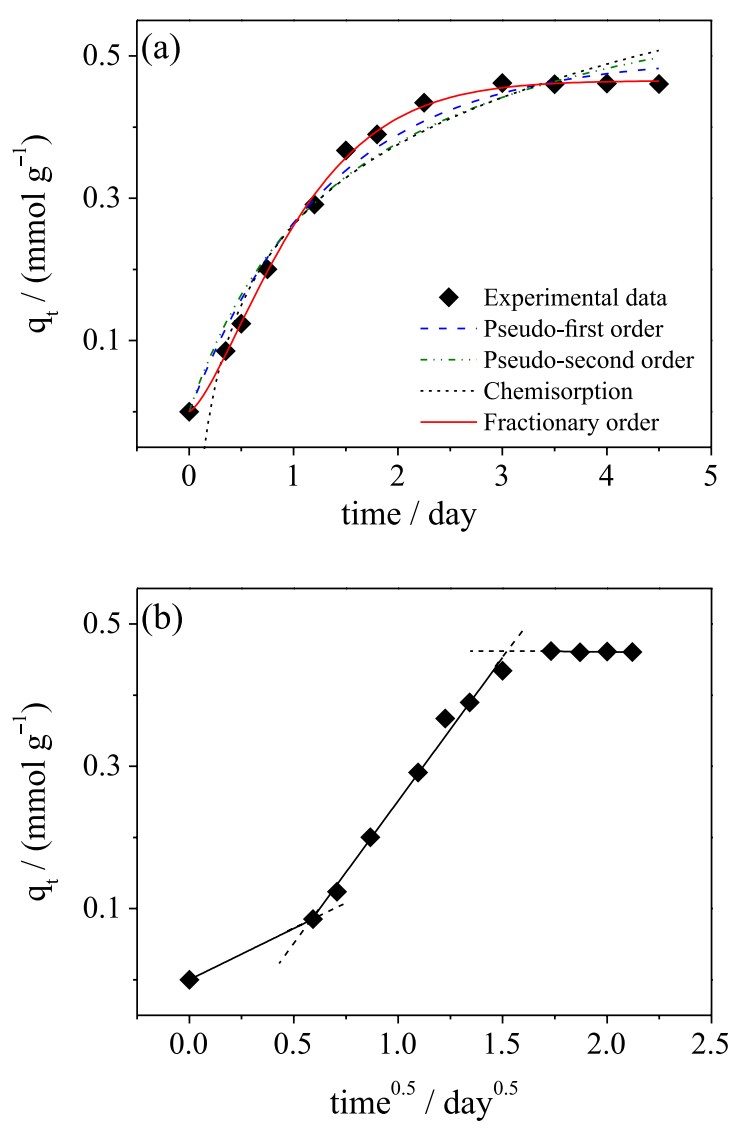

Figure 6. Adsorption kinetic of copper(II) for PDMS-net-P(VTMS-coDMAEMA) (PVD) from aqueous solutions: (a) simulations of kinetic models according to nonlinear fitting method; and (b) intraparticle diffusion.

the plot indicates that the intraparticle diffusion is not the only rate-limiting step.

\section{Equilibrium studies}

Figure 7 presents the adsorption isotherms of copper(II) for PVD in water and simulation curves obtained using the several adsorption models studied. The adsorption maximum was $0.48 \mathrm{mmol}$ of copper(II) (or $30 \mathrm{mg}$ ) per gram of material.

The parameters of the studied models for copper(II) adsorption of PVD are listed in Table 2. All models can be considered as adequate since $\mathrm{F}_{\text {exp }}<\mathrm{F}_{\text {crit }}$. However, the Sips model showed the best fit to the experimental data, with a low error function value (0.0302) and high $\mathrm{R}^{2}$ value (0.9982). This model is a combination of the Langmuir and Freundlich models. At low concentrations, it follows the Freundlich model, considering multilayer adsorption, while at high concentrations, it follows the Langmuir model, considering the existence of a saturation point, characterized by monolayer adsorption. ${ }^{60}$ The Sips model suggests which the surface is energetically heterogeneous. ${ }^{61}$ 
Table 1. Kinetic parameters for copper(II) adsorption on PDMS-net-P(VTMS-co-DMAEMA) (PVD)

\begin{tabular}{|c|c|c|c|}
\hline Kinetic model & Equation & Parameter & Data \\
\hline Pseudo-first order & $\mathrm{q}_{\mathrm{t}}=\mathrm{q}_{\mathrm{e}}\left[1-\exp \left(-\mathrm{k}_{1} \mathrm{t}\right)\right]$ & $\begin{array}{c}\mathrm{q}_{\mathrm{e}} /\left(\mathrm{mmol} \mathrm{g}^{-1}\right) \\
\mathrm{k}_{1} / \mathrm{h}^{-1} \\
\mathrm{R}^{2} \\
\mathrm{~F}_{\text {error }} \\
\mathrm{F}_{\text {exp }} \\
\mathrm{F}_{\text {crit }} \\
\end{array}$ & $\begin{array}{c}0.499 \\
0.758 \\
0.9819 \\
0.0228 \\
0.0181 \\
2.54 \\
\end{array}$ \\
\hline Pseudo-second order & $\mathrm{q}_{\mathrm{t}}=\frac{\mathrm{k}_{2} \mathrm{q}_{\mathrm{e}}^{2} \mathrm{t}}{1+\mathrm{k}_{2} \mathrm{q}_{\mathrm{e}}^{\mathrm{t}}}$ & $\begin{array}{c}\mathrm{q}_{\mathrm{e}} /\left(\mathrm{mmol} \mathrm{g}^{-1}\right) \\
\mathrm{k}_{2} /\left(\mathrm{g} \mathrm{mmol}^{-1} \mathrm{~h}^{-1}\right) \\
\mathrm{R}^{2} \\
\mathrm{~F}_{\text {error }} \\
\mathrm{F}_{\text {exp }} \\
\mathrm{F}_{\text {crit }} \\
\end{array}$ & $\begin{array}{c}0.667 \\
0.979 \\
0.9666 \\
0.0307 \\
0.0334 \\
2.54 \\
\end{array}$ \\
\hline Chemisorption (Elovich) & $\mathrm{q}_{\mathrm{t}}=\frac{1}{\beta} \operatorname{Ln}(\alpha \beta)+\frac{1}{\beta} \operatorname{Ln}(\mathrm{t})$ & $\begin{array}{c}\alpha /\left(\mathrm{mmol} \mathrm{g}^{-1} \mathrm{~h}^{-1}\right) \\
\beta /\left(\mathrm{g} \mathrm{mmol}^{-1}\right) \\
\mathrm{R}^{2} \\
\mathrm{~F}_{\text {error }} \\
\mathrm{F}_{\text {exp }} \\
\mathrm{F}_{\text {crit }} \\
\end{array}$ & $\begin{array}{c}0.816 \\
6.13 \\
0.9702 \\
0.0290 \\
0.0298 \\
2.54 \\
\end{array}$ \\
\hline Fractionary order (Avrami) & $\mathrm{q}_{\mathrm{t}}=\mathrm{q}_{\mathrm{e}}\left\{1-\exp \left[-\left(\mathrm{k}_{\mathrm{AV}} \mathrm{t}\right)\right]^{\mathrm{n}_{\mathrm{AV}}}\right\}$ & $\begin{array}{c}\mathrm{q}_{\mathrm{e}} /\left(\mathrm{mmol} \mathrm{g}^{-1}\right) \\
\mathrm{k}_{\mathrm{AV}} / \mathrm{h}^{-1} \\
\mathrm{n}_{\mathrm{AV}} \\
\mathrm{R}^{2} \\
\mathrm{~F}_{\text {error }} \\
\mathrm{F}_{\text {exp }} \\
\mathrm{F}_{\text {crit }}\end{array}$ & $\begin{array}{c}0.465 \\
0.872 \\
1.40 \\
0.9983 \\
0.00614 \\
0.00134 \\
2.71\end{array}$ \\
\hline Intraparticle diffusion & $\mathrm{q}_{\mathrm{t}}=\mathrm{k}_{\mathrm{id}} \sqrt{\mathrm{t}}+\mathrm{C}$ & $\mathrm{k}_{\mathrm{id}} /\left(\mathrm{mmol} \mathrm{g}^{-1} \mathrm{~h}^{-0.5}\right)$ & $0.403^{\mathrm{a}}$ \\
\hline
\end{tabular}

${ }^{a}$ Second stage. $\mathrm{q}_{\mathrm{t}}$ : Amount of metal ions adsorbed at time $\mathrm{t} ; \mathrm{q}_{\mathrm{e}}$ : amount of adsorbed metal at equilibrium per gram material; $\mathrm{t}$ : time of contact; $\mathrm{k}_{1}$ : $\mathrm{pseudo-}$ first order rate constant; $\mathrm{k}_{2}$ : pseudo-second order rate constant; $\alpha$ : initial adsorption rate of Elovich equation; $\beta$ : Elovich constant related to the extent of surface coverage and also to the activation energy involved in chemisorption; $\mathrm{k}_{\mathrm{AV}}$ : Avrami kinetic constant; $\mathrm{n}_{\mathrm{AV}}$ : fractionary reaction order (Avrami) related to adsorption mechanism; $\mathrm{k}_{\mathrm{id}}$ intraparticle diffusion rate constant.

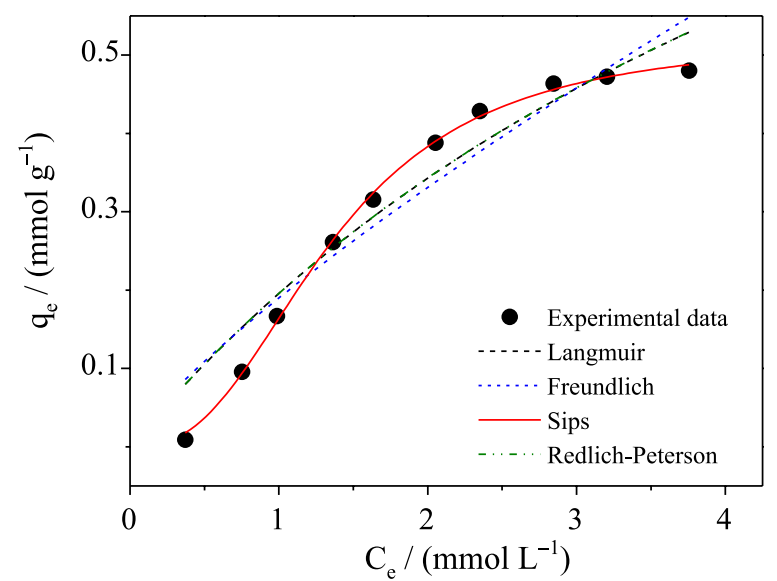

Figure 7. Adsorption isotherm of copper(II) for PDMS-net-P(VTMSco-DMAEMA) (PVD) from aqueous solutions and simulations obtained using isotherm models.

Copper(II) adsorption capacities of different functional materials are listed in Table 3. The polymeric network prepared in this work presents a copper(II) removal similar to some other materials that also contain PDMAEMA in their compositions, where the amount removed varies according to the amount of functional groups incorporated into each material.

\section{Desorption and reuse studies}

Figure 5 (effect of the $\mathrm{pH}$ on adsorption) showed that hybrid adsorbent did not adsorb significantly $\mathrm{Cu}^{\mathrm{II}}$ ions at $\mathrm{pH}<2$, which suggested that the adsorbed metal ions could possibly be desorbed in a solution with such $\mathrm{pH}$ values. Other similar studies ${ }^{62-64}$ have also reported effective desorption of adsorbed metals in acidic conditions.

Furthermore, adsorption-desorption cycles can be repeated to examine the reusability and metal recovery efficiency of the adsorbent. Figure 8 shows the $\mathrm{Cu}^{\mathrm{II}}$ ions removal after three sequential runs, with a reduction rate of about $5 \%$ after each cycle. This result indicates that the adsorbent can be regenerate and used several times.

\section{Conclusions}

This paper described the preparation and characterization 
Table 2. Isotherm parameters for copper(II) adsorption on PDMS-net-P(VTMS-co-DMAEMA) (PVD)

\begin{tabular}{|c|c|c|c|}
\hline Isotherm model & Equation & Parameter & Data \\
\hline \multirow{6}{*}{ Langmuir } & \multirow{6}{*}{$\mathrm{q}_{\mathrm{e}}=\frac{\mathrm{q}_{\mathrm{s}} \mathrm{K}_{\mathrm{L}} \mathrm{C}_{\mathrm{e}}}{1+\mathrm{K}_{\mathrm{L}} \mathrm{C}_{\mathrm{e}}}$} & $\mathrm{q}_{\mathrm{s}} /\left(\mathrm{mmol} \mathrm{g}^{-1}\right)$ & 1.38 \\
\hline & & $\mathrm{K}_{\mathrm{L}} /\left(\mathrm{mmol} \mathrm{L}^{-1}\right)$ & 0.165 \\
\hline & & $\mathrm{R}^{2}$ & 0.9318 \\
\hline & & $\mathrm{F}_{\text {error }}$ & 0.0565 \\
\hline & & $\mathrm{F}_{\text {exp }}$ & 0.111 \\
\hline & & $\mathrm{F}_{\text {crit }}$ & 2.93 \\
\hline \multirow{6}{*}{ Freundlich } & \multirow{6}{*}{$\mathrm{q}_{\mathrm{e}}=\mathrm{K}_{\mathrm{F}} \mathrm{C}_{\mathrm{e}}^{1 / \mathrm{n}_{\mathrm{F}}}$} & $\mathrm{K}_{\mathrm{F}} /\left(\mathrm{mmol} \mathrm{g}^{-1}\right)\left(\mathrm{mmol} \mathrm{L}^{-1}\right)^{\mathrm{n}}$ & 0.190 \\
\hline & & $\mathrm{n}_{\mathrm{F}}$ & 1.25 \\
\hline & & $\mathrm{R}^{2}$ & 0.9064 \\
\hline & & $\mathrm{F}_{\text {error }}$ & 0.0648 \\
\hline & & $\mathrm{F}_{\text {exp }}$ & 0.146 \\
\hline & & $F_{\text {crit }}$ & 2.93 \\
\hline \multirow{7}{*}{ Sips } & \multirow{7}{*}{$\mathrm{q}_{\mathrm{e}}=\frac{\mathrm{q}_{\mathrm{s}} \mathrm{K}_{\mathrm{s}} \mathrm{C}_{\mathrm{e}}^{1 / \mathrm{n}_{\mathrm{s}}}}{1+\mathrm{K}_{\mathrm{s}} \mathrm{C}_{\mathrm{e}}^{1 / \mathrm{n}_{\mathrm{s}}}}$} & $\mathrm{q}_{\mathrm{s}} /\left(\mathrm{mmol} \mathrm{g}^{-1}\right)$ & 0.522 \\
\hline & & $\mathrm{K}_{\mathrm{s}} /\left(\mathrm{mmol} \mathrm{L}^{-1}\right)$ & 0.458 \\
\hline & & $\mathrm{n}_{\mathrm{S}}$ & 0.386 \\
\hline & & $\mathrm{R}^{2}$ & 0.9982 \\
\hline & & $\mathrm{F}_{\text {error }}$ & 0.0302 \\
\hline & & $\mathrm{F}_{\text {exp }}$ & 0.0318 \\
\hline & & $\mathrm{F}_{\text {crit }}$ & 3.23 \\
\hline \multirow{7}{*}{ Redlich-Peterson } & \multirow{7}{*}{$\mathrm{q}_{\mathrm{e}}=\frac{\mathrm{K}_{\mathrm{R}} \mathrm{C}_{\mathrm{e}}}{1+\mathrm{a}_{\mathrm{R}} \mathrm{C}_{\mathrm{e}}^{\mathrm{g}}}$} & $\mathrm{K}_{\mathrm{R}} /\left(\mathrm{g} \mathrm{L}^{-1}\right)$ & 0.228 \\
\hline & & $\mathrm{a}_{\mathrm{R}} /\left(\mathrm{mmol} \mathrm{L}^{-1}\right)$ & 0.164 \\
\hline & & $\mathrm{g}$ & 1.00 \\
\hline & & $\mathrm{R}^{2}$ & 0.9221 \\
\hline & & $\mathrm{F}_{\text {error }}$ & 0.0605 \\
\hline & & $\mathrm{F}_{\text {exp }}$ & 0.127 \\
\hline & & $\mathrm{F}_{\text {crit }}$ & 3.23 \\
\hline
\end{tabular}

$\mathrm{q}_{\mathrm{e}}$ : Amount of adsorbed metal at equilibrium per gram material; $\mathrm{q}_{\mathrm{s}}$ : theoretical saturation capacity; $\mathrm{K}_{\mathrm{L}}:$ Langmuir affinity constant; $\mathrm{C}_{\mathrm{e}}$ : metal concentration at equilibrium; $\mathrm{K}_{\mathrm{F}}$ and $\mathrm{n}_{\mathrm{F}}$ : constant and exponent of Freundlich model, respectively; $\mathrm{K}_{\mathrm{S}}$ and $\mathrm{n}_{\mathrm{S}}$ : constant and exponent of Sips model, respectively; $\mathrm{K}_{\mathrm{R}}$ and $\mathrm{a}_{\mathrm{R}}$ : constant and $\mathrm{g}$ is exponent of Redlich-Peterson model, respectively.

Table 3. Comparison of maxima adsorption capacities $\left(\mathrm{q}_{\max }\right)$ of copper(II) on different materials

\begin{tabular}{lcc}
\hline Material & $\begin{array}{c}\mathrm{q}_{\max } / \\
\left(\mathrm{mmol} \mathrm{g}^{-1}\right)\end{array}$ & Reference \\
\hline PDMAEMA grafted regenerated cellulose & 5.25 & 1 \\
PDMAEMA hydrogel & 5.06 & 4 \\
PDMAEMA grafted starch & 2.12 & 32 \\
PDMAEMA functionalized activated & 0.49 & 33 \\
carbon & & \\
PDMAEMA/SiO 2 particles & 0.35 & 34 \\
PDMAEMA-cotton copolymer & 0.098 & 35 \\
PDMAEMA gel & 0.0063 & 36 \\
PVD & 0.48 & this work \\
\hline
\end{tabular}

DMAEMA: 2-(Dimethylamino)ethyl methacrylate; PDMAEMA: poly[2(dimethylamino)ethyl methacrylate]; PDMS: poly(dimethylsiloxane); PVD: PDMS-net-P(VTMS-co-DMAEMA);VTMS: vinyltrimethoxysilane.

of a hybrid polymer network based on PDMS and $\mathrm{P}$ (VTMS-co-DMAEMA). This material showed potential for adsorption of heavy metals such as copper(II) from aqueous solutions, achieving the highest efficiency at $\mathrm{pH}$ 5. The fractionary order and Sips models were the best ones from those studied to describe the adsorption kinetics

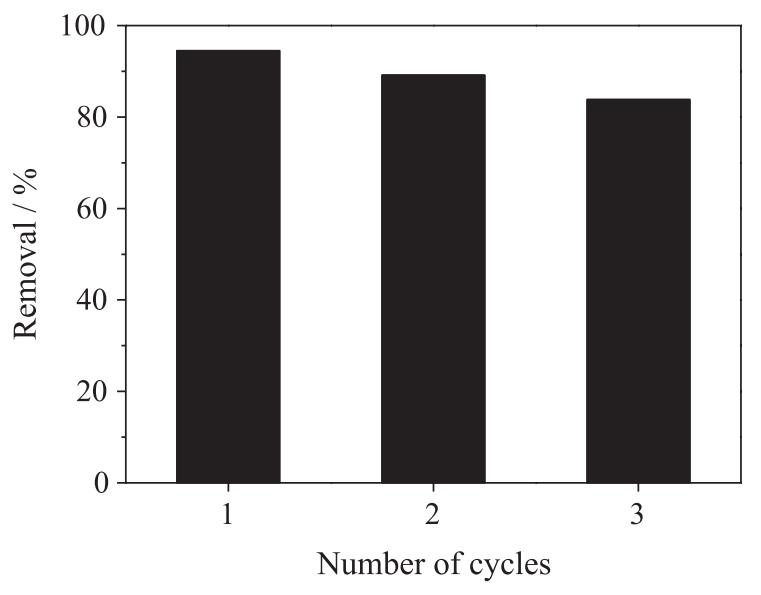

Figure 8. Cycles of $\mathrm{Cu}^{\mathrm{II}}$ adsorption-desorption for PDMS-net-P(VTMSco-DMAEMA) (PVD) from aqueous solutions.

and adsorbent-adsorbate interactions, respectively. The regeneration studies also revealed the good potential of this hybrid material as a reusable adsorbent.

\section{Supplementary Information}

Supplementary data are available free of charge at http://jbcs.sbq.org.br as PDF file. 


\section{Acknowledgments}

The authors are indebted to CAPES for the F. A. B. S. $\mathrm{PhD}$ fellowship; and CNPq, FAPEMIG, and FAPESP for their financial support.

\section{References}

1. Jiang, M.; Wang, J.; Li, L.; Pan, K.; Cao, B.; RSC Adv. 2013, 3, 20625.

2. Torres, J. D.; Faria, E. A.; Prado, A. G.; J. Hazard. Mater. 2006, 129, 239.

3. Jiang, Y.; Pang, H.; Liao, B.; J. Hazard. Mater. 2009, 164,1 .

4. Kavakh, P. A.; Yilmaz, Z.; Sen, M.; Sep. Sci. Technol. (Philadelphia, U. S.) 2007, 42, 1245.

5. Kampalanonwat, P.; Supaphol, P.; Ind. Eng. Chem. Res. 2011, $50,11912$.

6. Fu, F.; Wang, Q.; J. Environ. Manage. 2011, 92, 407.

7. Samiey, B.; Cheng, C. H.; Wu, J. N.; Materials 2014, 7, 673.

8. Hoffmann, F.; Cornelius, M.; Morell, J.; Fröba, M.; Angew. Chem., Int. Ed. 2006, 45, 3216.

9. Bozbas, S. K.; Ay, U.; Kayan, A.; Desalin. Water Treat. 2013, 51,7208 .

10. Zhang, Y.; Wang, X.; Liu, J.; Wu, L.; J. Chem. Eng. Data 2013, $58,1141$.

11. Larraza, I.; Lopez-Gonzalez, M.; Corrales, T.; Marcelo, G.; J. Colloid Interface Sci. 2012, 385, 24.

12. Pandey, S.; Mishra, S. B.; J. Sol-Gel Sci. Technol. 2011, $59,73$.

13. Rao, H.-X.; Liu, F.-N.; Zhang, Z.-Y.; J. Membr. Sci. 2007, 303, 132.

14. Pissetti, F. L.; Magosso, H. A.; Yoshida, I. V.; Gushikem, Y.; Myernyi, S. O.; Kholin, Y. V.; J. Colloid Interface Sci. 2007, $314,38$.

15. Pissetti, F. L.; Yoshida, I. V. P.; Gushikem, Y.; Kholin, Y. V.; Colloids Surf., A 2008, 328, 21.

16. dos Santos, M. P.; Magosso, H. A.; Yoshida, I. V. P.; Gushikem, Y.; Colloids Surf., A 2012, 398, 1.

17. Silva, F. A. B.; Pissetti, F. L.; J. Colloid Interface Sci. 2014, $416,95$.

18. Pissetti, F. L.; de Araújo, P. L.; Silva, F. A. B.; Poirier, G. Y.; J. Braz. Chem. Soc. 2015, 26, 266.

19. Zhang, X.; Lin, G.; Kumar, S. R.; Mark, J. E.; Polymer 2009, $50,5414$.

20. Mark, J. E.; Acc. Chem. Res. 2004, 37, 946.

21. Ibrahim, W. A. W.; Ismail, W. N. W.; Keyon, A. S. A.; Sanagi, M. M.; J. Sol-Gel Sci. Technol. 2011, 58, 602.

22. Silva, F. A. B.; Florenzano, F. H.; Pissetti, F. L.; J. Sol-Gel Sci. Technol. 2014, 72, 227.

23. Vankelecom, I. F. J.; Chem. Rev. (Washington, DC, U. S.) 2002 , 102, 3779 .
24. Lim, M.; Kim, D.; Seo, J.; Han, H.; Macromol. Res. 2014, 22, 1096.

25. Abe, Y.; Namiki, T.; Tuchida, K.; Nagao, Y.; Misono, T.; J. Non-Cryst. Solids 1992, 147, 47.

26. Crini, G.; Prog. Polym. Sci. 2005, 30, 38.

27. Fristak, V.; Pipiska, M.; Lesny, J.; Soja, G.; Friesl-Hanl, W.; Packova, A.; Environ. Monit. Assess. 2015, 187, 4093.

28. Neghlani, P. K.; Rafizadeh, M.; Taromi, F. A.; J. Hazard. Mater. 2011, 186, 182.

29. Yong, S. K.; Bolan, N.; Lombi, E.; Skinner, W.; Water, Air, Soil Pollut. 2013, 224, 1720.

30. Ge, Y.; Li, Z.; Xiao, D.; Xiong, P.; Ye, N.; J. Ind. Eng. Chem. (Amsterdam, Neth.) 2014, 20, 1765.

31. Huynh, H. T.; Tanaka, M.; Ind. Eng. Chem. Res. 2003, 42, 4050.

32. Zhang, L. M.; Chen, D. Q.; Colloids Surf., A 2002, 205, 231.

33. Zhu, S.; Yang, N.; Zhang, D.; Mater. Chem. Phys. 2009, 113, 784.

34. Gao, B.; Chen, Y.; Zhang, Z.; Appl. Surf. Sci. 2010, 257, 254.

35. Waly, A.; Abdel-Mohdy, F. A.; Aly, A. S.; Hebeish, A.; J. Appl. Polym. Sci. 1998, 68, 2151.

36. Tokuyama, H.; Ishihara, N.; React. Funct. Polym. 2010, 70, 610.

37. Panou, A. I.; Papadokostaki, K. G.; Tarantili, P. A.; Sanopoulou, M.; Eur. Polym. J. 2013, 49, 1803.

38. Wu, A.; Jia, J.; Luan, S.; Colloids Surf., A 2011, 384, 180.

39. Lagergren, S.; Kgl. Vetenskaps Akad. 1898, 24, 1.

40. Ho, Y. S.; McKay, G.; Process Biochem. (Oxford, U. K.) 1999 , $34,451$.

41. Elovich, S. Y.; Zhabrova, G. M.; Zh. Fiz. Khim. 1939, 13, 1761.

42. Cardoso, N. F.; Lima, E. C.; Pinto, I. S.; Amavisca, C. V.; Royer, B.; Pinto, R. B.; Alencar, W. S.; Pereira, S. F. P.; J. Environ. Manage. 2011, 92, 1237.

43. Weber, W.; Morris, J.; J. Sanit. Eng. Div., Am. Soc. Civ. Eng. 1963, 89, 31 .

44. Langmuir, I.; J. Am. Chem. Soc. 1918, 40, 1361.

45. Freundlich, H. M. F.; Z. Phys. Chem. 1906, 57, 385.

46. Ghaznavi, F.; Fatemi, S.; Joda, M.; Can. J. Chem. Eng. 2012, 90, 769 .

47. Redlich, O.; Peterson, D. L.; J. Phys. Chem. 1959, 63, 1024.

48. Skoog, D. A.; West, D. M.; Holler, F. J.; Crouch, S. R.; Fundamentals of Analytical Chemistry, $9^{\text {th }}$ ed.; Cengage Learning: Boston, 2013.

49. Chakrabarty, T.; Prakash, S.; Shahi, V. K.; J. Membr. Sci. 2013, 428, 86.

50. Estrada-Villegas, G. M.; Macossay, J.; Bucio, E.; J. Radioanal. Nucl. Chem. 2010, 284, 131.

51. Hernández-Martínez, A. R.; Bucio, E.; J. Radioanal. Nucl. Chem. 2010, 283, 559.

52. Gao, C.; Liu, M.; Chen, J.; Chen, C.; Polym. Adv. Technol. 2012, 23,389 . 
53. Chen, S.-C.; Kuo, S.-W.; Liao, C.-S.; Chang, F.-C.; Macromolecules (Washington, DC, U. S.) 2008, 41, 8865.

54. Pal, S.; Roy, S. G.; De, P.; Polym. Chem. 2014, 5, 1275.

55. Naeimi, M.; Karkhaneh, A.; Barzin, J.; Khorasani, M. T.; Ghaffarieh, A.; J. Appl. Polym. Sci. 2013, 127, 3940.

56. Li, S.; Qin, F.; Qin, P.; Karim, M. N.; Tan, T.; Green Chem. 2013, 15, 2180.

57. Bodas, D.; Khan-Malek, C.; Sens. Actuators, B 2007, 123, 368.

58. Hillborg, H.; Gedde, U. W.; IEEE Trans. Dielectr. Electr. Insul. 1999, 6, 703.

59. Srivastava, V. C.; Mall, I. D.; Mishra, I. M.; J. Hazard. Mater. 2006, 134, 257.

60. Royer, B.; Cardoso, N. F.; Lima, E. C.; Vaghetti, J. C. P.; Simon, N. M.; Calvete, T.; Veses, R. C.; J. Hazard. Mater. 2009, 164, 1213.
61. Foo, K. Y.; Hameed, B. H.; Chem. Eng. J. (Amsterdam, Neth.) 2010, 156, 2.

62. Ge, F.; Li, M.-M.; Ye, H.; Zhao, B.-X.; J. Hazard. Mater. 2012 , 211-212, 366.

63. Hao, Y. M.; Man, C.; Hu, Z. B.; J. Hazard. Mater. 2010, 184, 392.

64. Emik, S.; React. Funct. Polym. 2014, 75, 63.

Submitted: January 18, 2016

Published online: April 8, 2016

FAPESP has sponsored the publication of this article. 